\title{
RESEARCH
}

Open Access

\section{Effect of surgery on survival in patients with stage III N2 small cell lung cancer: propensity score matching analysis and nomogram development and validation}

Yanfei Chai ${ }^{1}$ Yuchao Ma ${ }^{1}$, Wei Feng ${ }^{1}$, Hongwei Lu ${ }^{2^{*}}$ and Longyu Jin $^{1{ }^{*}}$ (D)

\begin{abstract}
Background: The standard treatment of stage III N2 small cell lung cancer (SCLC) is concurrent chemoradiation, and surgery is not recommended. This study was aimed to evaluate whether surgery has survival benefits in patients with stage III N2 SCLC and investigate the factors influencing survival of surgery.

Methods: Patients diagnosed with stage T1-4N2M0 SCLC from 2004 to 2015 were selected from the Surveillance Epidemiology End Results database. Propensity score matching (PSM) was used to balance confounders between patients who underwent surgery and those treated with radiation and/or chemotherapy. We compared overall survival (OS) of the two groups using Kaplan-Meier curves and a Cox proportional hazard model. We also identified prognostic factors in patients with surgical resection, and a nomogram was developed and validated for predicting postoperative OS.

Results: -A total of 5576 patients were included in the analysis; of these, 211 patients underwent surgery. PSM balanced the differences between the two groups. The median OS was longer in the surgery group than in the non-surgery group (20 vs. 15 months; $p=0.0024$ ). Surgery was an independent prognostic factor for longer OS in the multivariate Cox regression analysis, and subgroup analysis revealed a higher survival rate in T1 stage patients treated with surgery (hazard ratio $=0.565,95 \%$ confidence interval: $0.401-0.798 ; p=0.001$ ). In patients who underwent surgery, four prognostic factors, including age, T stage, number of positive lymph nodes, and radiation, were selected into nomogram development for predicting postoperative OS. C-index, decision curve analyses, integrated discrimination improvement, and time-dependent receiver operating characteristics showed better performance in nomogram than in the tumor-node-metastasis staging system. Calibration plots demonstrated good consistency between nomogram predicted survival and actual observed survival. The patients were stratified into three different risk groups by prognostic scores and Kaplan-Meier curves showed significant difference between these groups.
\end{abstract}

\footnotetext{
*Correspondence: hongweilu@csu.edu.cn; jinlongyu1123@163.com

${ }^{2}$ Center for Experimental Medicine, The Third Xiangya Hospital of Central

South University, No. 138 Tongzipo Road, Changsha 410013, China

'Departments of Cardiothoracic Surgery, The Third Xiangya Hospital of

Central South University, No. 138 Tongzipo Road, Changsha 410013, China
}

(c) The Author(s). 2021 Open Access This article is licensed under a Creative Commons Attribution 4.0 International License, which permits use, sharing, adaptation, distribution and reproduction in any medium or format, as long as you give appropriate credit to the original author(s) and the source, provide a link to the Creative Commons licence, and indicate if changes were made. The images or other third party material in this article are included in the article's Creative Commons licence, unless indicated otherwise in a credit line to the material. If material is not included in the article's Creative Commons licence and your intended use is not permitted by statutory regulation or exceeds the permitted use, you will need to obtain permission directly from the copyright holder. To view a copy of this licence, visit http://creativecommons.org/licenses/by/4.0/ The Creative Commons Public Domain Dedication waiver (http://creativecommons.org/publicdomain/zero/1.0/) applies to the data made available in this article, unless otherwise stated in a credit line to the data. 
Conclusions: These results indicate that surgery can prolong survival in patients with operable stage III N2 SCLC, particularly those with $\mathrm{T} 1$ disease. A nomogram that includes age, $\mathrm{T}$ stage, number of positive lymph nodes, and radiation can be used to predict their long-term postoperative survival.

Keywords: Small cell lung cancer, Surgery, N2, Prognosis, Nomogram

\section{Introduction}

Lung cancer is the most common cancer worldwide with a high mortality. In 2020, there were an estimated 228,820 new lung cancer cases and 135,720 lung cancer deaths in the USA [1]. In China, there were 815,563 new cases and 714,699 deaths due to lung cancer in 2020 [2]. Small cell lung cancer (SCLC) accounts for $15 \%$ of all lung cancer cases with high-grade malignancy and has extremely poor prognosis [3].

The Veterans Administration Lung Cancer Study Group (VALCSG) staging system that is used to determine whether radiation is an appropriate treatment for a patient classifies SCLC as limited disease (LD) or extensive disease. At the time of diagnosis, almost $75 \%$ of SCLC cases are metastatic and the 5-year overall survival (OS) rate is $<3 \%$. Moreover, $80 \%$ of patients with $\mathrm{LD}$ SCLC have regional disease with lymph node metastasis or invasion of intrathoracic organs [4].

The 8th edition of American Joint Committee on Cancer (AJCC) tumor-node-metastasis (TNM) staging for lung cancer released in 2015 is recommended for SCLC staging. Compared to the VALCSG staging system, TNM staging is based on more detailed information on the primary tumor and metastatic lymph nodes. According to National Comprehensive Cancer Network $(\mathrm{NCCN})$ guidelines, surgery is only recommended in patients with stage I-IIA (T1-2, N0, M0) SCLC after standard clinical staging evaluation. These patients without lymph node involvement can benefit from surgical resection, which is associated with a median survival of 35-79 months [5-10]. Surgery with adjuvant chemotherapy can also improve long-term survival compared to concurrent chemoradiation. In patients with lymph node metastasis, concurrent chemoradiation is the cornerstone of treatment. Although some retrospective studies found that surgery combined with chemoradiation can enhance survival in stage II/III SCLC [5, 1114], this has not been demonstrated in clinical trials.

Lung cancer with mediastinal lymph node metastasis is remarkably heterogeneous. N2 disease is classified as 3 categories: N2a1, a single metastatic N2 nodal station without N1 involvement (skipping metastasis); N2a2, a single metastatic $\mathrm{N} 2$ nodal station with $\mathrm{N} 1$ involvement; and N2b, involvement of multiple N2 nodal stations [15]. Surgery with chemoradiation can improve OS in patients with N2a1 and N2a2 non-small cell lung cancer (NSCLC) [16, 17]; however, it remains unclear whether surgery has survival benefits in patients with N2 SCLC. To answer this question, in the present study we investigated factors that influence the clinical outcome of patients with stage III N2 SCLC treated with surgery, and a predictive nomogram was developed and validated based on these factors.

\section{Materials and methods Patient selection}

Patient information was obtained from National Cancer Institute Surveillance, Epidemiology, and End Results (SEER) records. Patients diagnosed with SCLC from 2004 to 2015 in the SEER database were screened using SEER*Stat 8.3.8 software. Inclusion criteria were as follows: histology code 8041-8045 (ICD-O-3); stage T14N2M0; surgery codes including wedge resection, segment resection, lobectomy, and pneumonectomy; radiation code of beam radiation; and primary site code of lobe. Exclusion criteria were as follows: patients without surgery, radiation, or chemotherapy; age $>80$ years; and missing information on tumor size and survival time.

Patient data included in the analysis were age, sex, year of diagnosis, race, laterality, primary site, grade, tumor size, AJCC T stage, radiation, and chemotherapy. AJCC 6th edition $\mathrm{T}$ stage was converted to AJCC 8th edition T stage based on tumor size. To identify factors influencing patient outcome after surgery, information on the procedure (sublobectomy, lobectomy, or pneumonectomy), number of examined lymph nodes, and number of positive lymph nodes was obtained.

\section{Propensity score matching (PSM) and survival analysis in all patients}

The primary outcome was OS. OS was defined as the length of time from the start of treatment to date of death or last follow-up. Categorical variables were recorded as frequencies and proportions, and continuous variables were recorded as means with standard deviations. The chi-squared test was used to analyze categorical variables, while the Student's $t$ test was used for normally distributed variables.

PSM was performed to reduce the influence of confounders in comparisons between the surgery and nonsurgery groups. Covariates including age, sex, year of diagnosis, race, primary tumor site, tumor grade, tumor size, and AJCC T stage were included in the PSM. The matching ratio was set as 1:1 using a caliper of 0.2 . A 
standardized difference $<10 \%$ was considered wellbalanced matching.

Kaplan-Meier survival analysis with the log-rank test was performed to compare OS between surgery and non-surgery groups before and after PSM. A univariate Cox proportional hazards model was used to evaluate the prognostic values of various factors based on estimated hazard ratios (HRs) and 95\% confidence intervals (CIs). Covariates with $p<0.10$ in the univariate Cox analysis were entered into a multivariate Cox proportional hazards model. Backward step analysis was performed to identify factors associated with OS, and covariates with $p<0.05$ were considered independent prognostic factors. We also compared the survival benefit of surgery in a subgroup analysis and generated forest plots with HRs and 95\% CIs.

\section{Development and validation of a nomogram in surgery patients}

To identify prognostic factors in patients treated with surgery, the patients were stratified according to the surgical procedure, number of examined lymph nodes, and number of positive lymph nodes. Backward stepwise selection with the Akaike information criterion was used to select variables into the multivariate Cox proportional hazards regression model. Based on the Cox models, a nomogram was developed to predict 1-, 3-, and 5-year OS probability.

The discriminatory power of the nomogram was assessed with Harrell's $C$ index, decision curve analyses (DCA), and integrated discrimination improvement (IDI) compared with the TNM staging system. The area under the curve (AUC) of time-dependent receiver operating characteristics (ROC) was calculated for each month from months 10 to 100 . AUC of the nomogram from 1 to 5 years was calculated and compared with the TNM staging system.

Internal validation for the nomogram was performed with 1000 bootstrap resamples. A calibration plot was generated to compare predicted and actual OS probabilities. The patients were stratified into three different risk groups according to prognostic scores, and the cut-off values were calculated using "surv_cutpoint" in R software, which could determine the optimal cutpoint for continuous variables. Kaplan-Meier survival curves were used to compare survival differences between different groups.

Statistical analyses were performed with $\mathrm{R}$ version 4.0.3 (R Foundation for Statistical Computing, Vienna, Austria, http://www.r-project.org). The R packages "survival", "survminer", "foreign", "MatchIt", "rms", and "timeROC" were used for PSM and nomogram development and validation. A 2 -sided $p$ value $<0.05$ was taken as the cut-off for statistical significance.

\section{Results}

\section{Patient characteristics}

A total of 5567 patients with SCLC were selected from the SEER database (Fig. 1). Patients' baseline characteristics are presented in Table 1. Of these patients, 211 underwent surgery and 5356 received chemotherapy or radiation or both. The median age was 66 years for the surgery group and 67 years for the non-surgery group. There were significant differences in pathologic grade, tumor site, tumor size, and $\mathrm{T}$ stage between the two groups. In the surgery group, $65.4 \%$ patients had a definite pathologic grade, $65.9 \%$ had a tumor $<3 \mathrm{~cm}$ in diameter, and $70.2 \%$ were diagnosed as $\mathrm{T} 1$ or $\mathrm{T} 2 \mathrm{a}$ as compared to $29.9 \%, 36.6 \%$, and $35.2 \%$, respectively, in the non-surgery group. Thus, in general, surgery was performed in patients with a lower tumor burden.

In the surgery group, 125 patients (59.3\%) received chemoradiation, $50(23.7 \%)$ received chemotherapy, 7 (3.3\%) received radiation, and $29(13.7 \%)$ were treated with surgery alone. In the non-surgery group, 4121 patients $(76.9 \%)$ were treated with chemoradiation, 1066 (19.9\%) with chemotherapy, and 169 (3.2\%) with radiation.

\section{Survival analyses in all patients}

At the time of study, 4700 deaths were recorded with a median follow-up of 14 months (range, 1-155 months). Before PSM, the median OS was 20 months $(95 \% \mathrm{CI}$, 18-25 months) for the surgery group and 15 months (95\% CI, 14-15 months) for the non-surgery group; the 5 -year survival rates were $23.8 \%$ and $13.6 \%$, respectively $(p<0.001)$ (Fig. 2A).

After PSM, there were 205 patients in each group. Differences in patients' characteristics between the two groups were well balanced (Table 1). The Kaplan-Meier survival analysis after PSM confirmed that surgery conferred a survival benefit (Fig. 2B). In the univariate analysis, age, tumor size, $\mathrm{T}$ stage, surgery, and radiation had significant impacts on survival. Patients treated with chemotherapy also showed better prognosis $(\mathrm{HR}=$ $0.743)$, but the difference was not significant ( $p=0.093)$. Given the strong correlation between tumor size and $\mathrm{T}$ stage $(r=0.715, p<0.001)$, we selected $\mathrm{T}$ stage for multivariate Cox analyses and found that age, T stage, surgery, and radiation were independent prognostic factors in patients with stage III N2 SCLC (Table 2). Patients treated with surgery $(\mathrm{HR}=0.572,95 \% \mathrm{CI} 0.453-$ $0.723 ; p<0.001)$ and radiation $(\mathrm{HR}=0.519,95 \% \mathrm{CI}$ $0.401-0.67 ; p<0.001)$ had longer survival, while age $\geq$ 70 years $(\mathrm{HR}=1.606,95 \%$ CI $1.197-2.156 ; p=0.002)$ and T3/T4 $(\mathrm{HR}=1.568,95 \%$ CI $1.189-2.068 ; p=0.001)$ were associated with unfavorable prognosis.

In the subgroup analysis, surgery had greater benefit for OS in patients who were $<60$ and $\geq 70$ years of age, 


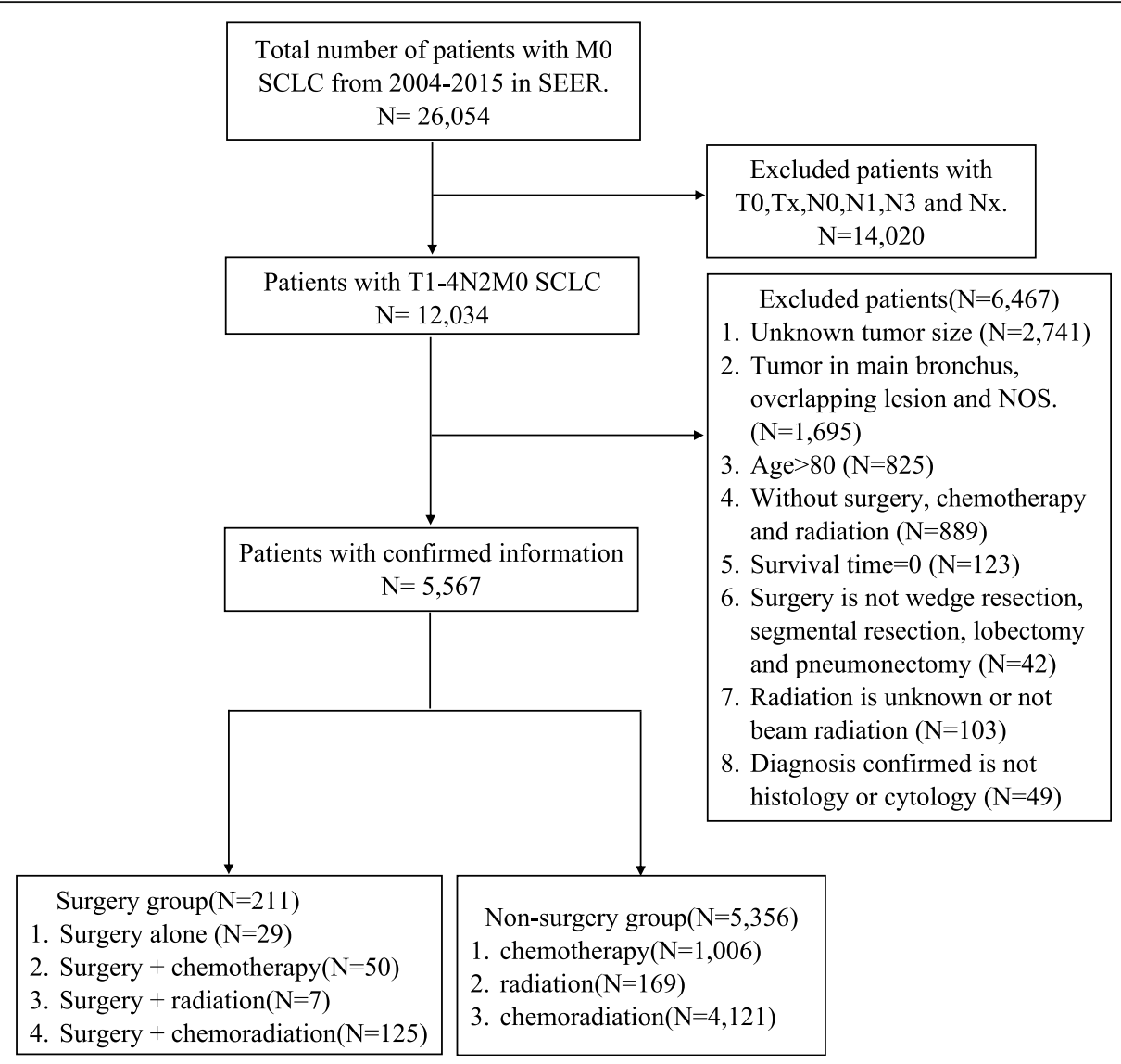

Fig. 1 Flow chart of patient selection

diagnosed between 2004 and 2009, male, had a tumor on the left side, had a tumor with a definite pathologic grade, and stage T1 (Fig. 3). Surgery improved the prognosis of patients regardless of whether they received radiation or chemotherapy.

\section{Prognostic factors in SCLC patients treated with surgery} Detailed information on the surgery performed on SCLC patients including procedure, number of examined lymph nodes, and number of positive lymph nodes is presented in Table 3. As survival rates were similar between patients with $\geq 3$ positive lymph nodes and those with unknown status $(\mathrm{HR}=0.976 ; p=0.91)$, we combined the two groups for comparison with patients with $\leq 2$ positive lymph nodes. In both uni- and multivariate analyses, age, $\mathrm{T}$ stage, number of positive lymph nodes, and radiation were significant independent prognosis factors (Table 4).

\section{Nomogram for predicting outcome of SCLC following surgery}

Based on the Cox regression model, 4 variablesnamely, age, $\mathrm{T}$ stage, number of positive lymph nodes, and radiation-were selected to construct a nomogram to predict 1-, 3-, and 5-year OS probability in patients with stage III N2 SCLC who were treated with surgery (Fig. 4). Table S1 shows the prognostic score for different variables.

The Harrell's C-index for the established nomogram (0.618, 95\% CI 0.571-0.665) was significantly higher than that of the TNM staging system $(0.548,95 \% \mathrm{CI}$ $0.505-0.591 ; p<0.001)$. DCA curve confirmed the clinical usefulness of the nomogram compared with the TNM staging system (Fig. 5). The 1-/3-/5-year IDI of nomogram compared with the TNM staging system was $2.86 \%(p=0.025), 4.49 \%(p=0.020)$, and $4.24 \%(p=0.019)$, respectively. The timedependent ROC also showed higher AUCs of the nomogram than that of the TNM staging system (Figure S1). The AUCs of the two predict models from 1 to 5 year were presented and compared in Table S2. We also compared this nomogram with a previous nomogram with 7 predictors for resected SCLC [18]. The time-dependent ROC showed this nomogram with less predictors was not inferior to the previous nomogram (Figure S2). 
Table 1 Baseline characteristics in surgery and non-surgery patients with stage III N2 SCLC before and after PSM

\begin{tabular}{|c|c|c|c|c|c|c|}
\hline \multirow[t]{3}{*}{ Variable } & \multicolumn{3}{|l|}{ Before PSM } & \multicolumn{3}{|l|}{ After PSM } \\
\hline & Non-surgery & Surgery & $p$ & Non-surgery & Surgery & $p$ \\
\hline & $N(\%)$ & $N(\%)$ & & $N(\%)$ & $N(\%)$ & \\
\hline Total & $5356(100)$ & $211(100)$ & & 205(100) & 205(100) & \\
\hline Age (years) median (range) & $66(31-80)$ & $67(38-80)$ & 0.132 & $66(37-80)$ & $67(38-80)$ & 0.366 \\
\hline \multicolumn{7}{|l|}{ Age } \\
\hline$<60$ years & $1417(26.5)$ & $46(21.8)$ & 0.255 & $49(23.9)$ & $44(21.5)$ & 0.804 \\
\hline $60-69$ years & $2132(39.8)$ & $85(40.3)$ & & $84(41.0)$ & $84(41.0)$ & \\
\hline$\geq 70$ years & 1807 (33.7) & $80(37.9)$ & & $72(35.1)$ & 77 (37.6) & \\
\hline \multicolumn{7}{|l|}{ Race } \\
\hline White & $4615(86.2)$ & $191(90.5)$ & 0.195 & $190(92.7)$ & $185(90.2)$ & 0.662 \\
\hline Black & $520(9.7)$ & $14(6.6)$ & & $10(4.9)$ & $14(6.8)$ & \\
\hline Other & $221(4.1)$ & $6(2.8)$ & & $5(2.4)$ & $6(2.9)$ & \\
\hline \multicolumn{7}{|l|}{ Sex } \\
\hline Male & $2438(45.5)$ & $95(45.0)$ & 0.943 & $101(49.3)$ & $92(44.9)$ & 0.429 \\
\hline Female & $2918(54.5)$ & $116(55.0)$ & & $104(50.7)$ & $113(55.1)$ & \\
\hline \multicolumn{7}{|l|}{ Year } \\
\hline 2004-2009 & $2665(49.8)$ & $99(46.9)$ & 0.46 & $100(48.8)$ & $96(46.8)$ & 0.767 \\
\hline 2010-2015 & $2691(50.2)$ & $112(53.1)$ & & 105 (51.2) & $109(53.2)$ & \\
\hline \multicolumn{7}{|l|}{ Grade } \\
\hline 1 & $10(0.2)$ & $3(1.4)$ & $<0.001$ & $1(0.5)$ & $3(1.5)$ & 0.374 \\
\hline$\|$ & $16(0.3)$ & $9(4.3)$ & & $5(2.4)$ & $4(2.0)$ & \\
\hline III & 505 (9.4) & 69 (32.7) & & 76 (37.1) & 68 (33.2) & \\
\hline IV & 1068 (19.9) & $57(27.0)$ & & $42(20.5)$ & $57(27.8)$ & \\
\hline Unknown & 3757 (70.1) & $73(34.6)$ & & 81 (39.5) & 73 (35.6) & \\
\hline \multicolumn{7}{|l|}{ Lateral } \\
\hline Right & 3289 (61.4) & 105 (49.8) & 0.001 & $104(50.7)$ & $102(49.8)$ & 0.921 \\
\hline Left & 2067 (38.6) & $106(50.2)$ & & $101(49.3)$ & $103(50.2)$ & \\
\hline \multicolumn{7}{|l|}{ Tumor site } \\
\hline RUL & 2185 (40.8) & $57(27.0)$ & 0.001 & $64(31.2)$ & $56(27.3)$ & 0.822 \\
\hline $\mathrm{RML}$ & $289(5.4)$ & $8(3.8)$ & & $5(2.4)$ & $8(3.9)$ & \\
\hline RLL & $815(15.2)$ & $40(19.0)$ & & 35 (17.1) & 38 (18.5) & \\
\hline LUL & 1547 (28.9) & 77 (36.5) & & 70 (34.1) & 74 (36.1) & \\
\hline LLL & $520(9.7)$ & 29 (13.7) & & $31(15.1)$ & $29(14.1)$ & \\
\hline \multicolumn{7}{|l|}{ Tumor size } \\
\hline$\leq 3 \mathrm{~cm}$ & 1960 (36.6) & $139(65.9)$ & $<0.001$ & $126(61.5)$ & $133(64.9)$ & 0.709 \\
\hline $3-5 \mathrm{~cm}$ & 1426 (26.6) & $51(24.2)$ & & $59(28.8)$ & $51(24.9)$ & \\
\hline $5-7 \mathrm{~cm}$ & 954 (17.8) & $13(6.2)$ & & $10(4.9)$ & $13(6.3)$ & \\
\hline$>7 \mathrm{~cm}$ & $1016(19.0)$ & $8(3.8)$ & & $10(4.9)$ & $8(3.9)$ & \\
\hline \multicolumn{7}{|l|}{ T stage } \\
\hline T1a & $118(2.2)$ & $19(9.0)$ & $<0.001$ & $22(10.7)$ & $19(9.3)$ & 0.944 \\
\hline $\mathrm{T} 1 \mathrm{~b}$ & $510(9.5)$ & $41(19.4)$ & & $35(17.1)$ & 38 (18.5) & \\
\hline T1c & $525(9.8)$ & 27 (12.8) & & $33(16.1)$ & $27(13.2)$ & \\
\hline T2a & 734 (13.7) & $64(30.3)$ & & 55 (26.8) & $61(29.8)$ & \\
\hline $\mathrm{T} 2 \mathrm{~b}$ & $368(6.9)$ & $11(5.2)$ & & $14(6.8)$ & $11(5.4)$ & \\
\hline
\end{tabular}


Table 1 Baseline characteristics in surgery and non-surgery patients with stage III N2 SCLC before and after PSM (Continued)

\begin{tabular}{|c|c|c|c|c|c|c|}
\hline \multirow[t]{3}{*}{ Variable } & \multicolumn{3}{|l|}{ Before PSM } & \multicolumn{3}{|l|}{ After PSM } \\
\hline & Non-surgery & Surgery & $p$ & Non-surgery & Surgery & $p$ \\
\hline & $N(\%)$ & $N(\%)$ & & $N(\%)$ & $N(\%)$ & \\
\hline T3 & $591(11.0)$ & $10(4.7)$ & & $9(4.4)$ & $10(4.9)$ & \\
\hline $\mathrm{T} 4$ & 2510 (46.9) & 39 (18.5) & & $37(18.0)$ & 39 (19.0) & \\
\hline \multicolumn{7}{|c|}{ Chemotherapy } \\
\hline Yes & 5187 (96.8) & $175(82.9)$ & $<0.001$ & 199 (97.1) & $170(82.9)$ & $<0.001$ \\
\hline No & 169 (3.2) & $36(17.1)$ & & $6(2.9)$ & 35 (17.1) & \\
\hline \multicolumn{7}{|l|}{ Radiation } \\
\hline Yes & $4290(80.1)$ & 132 (62.6) & $<0.001$ & $168(82.0)$ & $129(62.9)$ & $<0.001$ \\
\hline No & 1066 (19.9) & 79 (37.4) & & $37(18.0)$ & 76 (37.1) & \\
\hline
\end{tabular}

PSM propensity score matching, $R U L$ right upper lobe, $R M L$ right middle lobe, $R L L$ right lower lobe, $L U L$ left upper lobe, $L L L$ left lower lobe

The calibration plots showed a high degree of coincidence between OS predicted with the nomogram and actual OS (Fig. 6). According to prognostic score, the patients were stratified into three groups: low risk (0-119.5), middle risk (119.6-167.5), and high risk (167.6-279.5). Kaplan-Meier survival curves also showed significant difference between these groups (Fig. 7).

\section{Discussion}

In this retrospective study, we screened cases in the SEER database to analyze the efficacy of surgery vs. other treatment modalities in the multidisciplinary management of stage III N2 SCLC. As most patients who underwent surgery had a low tumor burden, we used PSM to balance confounders in the surgery and non-surgery groups. Our results indicated that surgery markedly improved the prognosis of patients with stage III N2 SCLC, especially those with stage T1 disease. Additionally, the number of positive lymph nodes was an independent prognostic factor in patients who underwent surgery.

SCLC is associated with a high rate of malignancy and is prone to extensive metastasis. The recurrence rate after aggressive multidisciplinary treatment is also extremely high, while the OS rate is just $6.5 \%$ for all stages

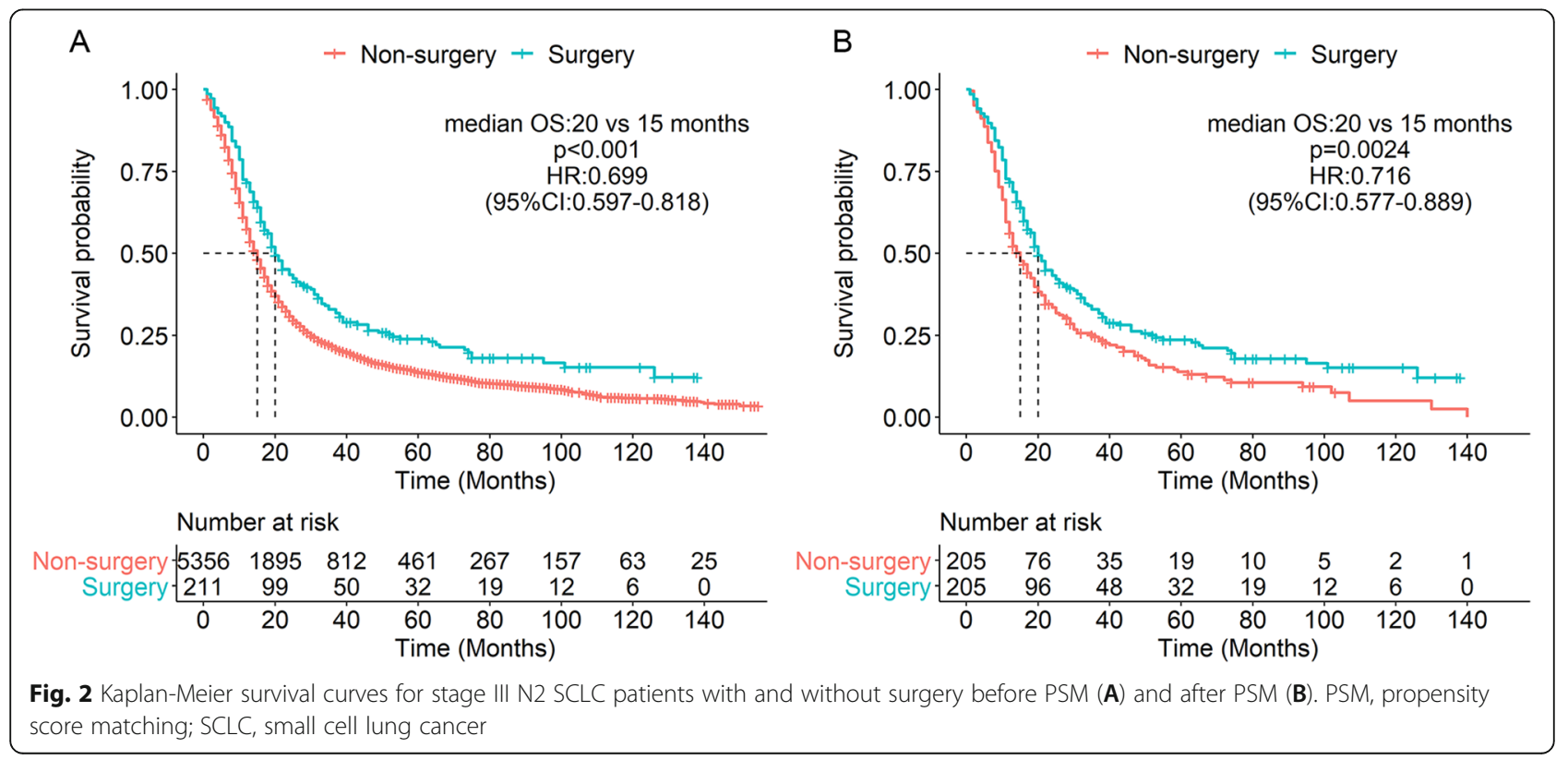


Table 2 Cox regression analyses of prognostic variables for OS after PSM

\begin{tabular}{|c|c|c|c|c|}
\hline \multirow[t]{2}{*}{ Variable } & \multicolumn{2}{|l|}{ Univariate analysis } & \multicolumn{2}{|l|}{ Multivariate analysis } \\
\hline & HR $(95 \% \mathrm{Cl})$ & $p$ & HR $(95 \% \mathrm{Cl})$ & $p$ \\
\hline Age & & 0.007 & & \\
\hline$<60$ years & 1 & & 1 & \\
\hline $60-69$ years & $1.312(0.984-1.750)$ & 0.064 & $1.217(0.911-1.626)$ & 0.185 \\
\hline$\geq 70$ years & $1.588(1.186-2.126)$ & 0.002 & $1.606(1.197-2.156)$ & 0.002 \\
\hline Race (other vs White) & $0.976(0.670-1.420)$ & 0.898 & & \\
\hline Sex (female vs male) & $0.934(0.752-1.160)$ & 0.537 & & \\
\hline Year (2010-2015 vs 2004-2009) & $0.952(0.764-1.190)$ & 0.665 & & \\
\hline Lateral (left vs right) & 1.068(0.994- 1.148) & 0.072 & $1.072(0.997-1.152)$ & 0.061 \\
\hline Grade & & 0.800 & & \\
\hline$|-|||$ & 1 & & & \\
\hline IV & $0.936(0.708-1.238)$ & 0.645 & & \\
\hline Unknown & $1.027(0.801-1.317)$ & 0.831 & & \\
\hline Site & & 0.100 & & \\
\hline RUL & 1 & & & \\
\hline RML & $1.436(0.748-2.757)$ & 0.277 & & \\
\hline RLL & $0.808(0.578-1.130)$ & 0.212 & & \\
\hline LUL & $1.107(0.845-1.449)$ & 0.461 & & \\
\hline LLL & $1.266(0.904-1.775)$ & 0.170 & & \\
\hline Tumor size & & 0.020 & & \\
\hline$\leq 3 \mathrm{~cm}$ & 1 & & & \\
\hline $3-5 \mathrm{~cm}$ & $1.173(0.916-1.502)$ & 0.206 & & \\
\hline$>5 \mathrm{~cm}$ & $1.661(1.168-2.362)$ & 0.005 & & \\
\hline T stage & & 0.020 & & \\
\hline $\mathrm{T} 1$ & 1 & & 1 & \\
\hline $\mathrm{T} 2$ & $1.050(0.817-1.350)$ & 0.703 & $1.023(0.796-1.316)$ & 0.859 \\
\hline $\mathrm{T} 3 / \mathrm{T} 4$ & $1.464(1.112-1.925)$ & 0.007 & $1.568(1.189-2.068)$ & 0.001 \\
\hline Surgery & $0.716(0.577-0.889)$ & 0.003 & $0.572(0.453-0.723)$ & $<0.001$ \\
\hline Radiation & $0.625(0.493-0.793)$ & $<0.001$ & $0.519(0.401-0.670)$ & $<0.001$ \\
\hline Chemotherapy & $0.743(0.525-1.050)$ & 0.093 & $0.796(0.538-1.178)$ & 0.253 \\
\hline
\end{tabular}

PSM propensity score matching, OS overall survival, $\mathrm{Cl}$ confidence interval, $H R$ hazards ratio

$[1,3,4,19]$. Early studies indicated that surgery did not improve survival over chemoradiation [20-22]; however, in these studies the diagnostic approaches were inadequate for accurately staging and selecting operable patients, and the rate of complete resection was relatively low. With improvements in minimally invasive surgery techniques and diagnostic methods and the establishment of oncology as a concept, radical resection has increasingly been applied according to more rigorous criteria [5]. More effective chemotherapy and radiation regimens have also improved survival rates after surgery $[23,24]$. A series of retrospective studies confirmed that surgery as a part of multimodal management strategy for early-stage SCLC could improve clinical outcomes [6, 25-28], and surgery is now recommended for cT12NOMO SCLC in the NCCN guidelines.

Chemoradiation was considered the standard of care for stage III SCLC with mediastinal lymph node metastasis $[24,29]$. These patients seldom have resectable tumors, as N2 disease is highly heterogeneous. Only $2.6 \%$ of N2 patients in the SEER database underwent surgery as compared to $13.5 \%$ of $\mathrm{N} 1$ and $17.2 \%$ of N0 patients. Given these statistics, it is difficult to conduct randomized control trials for N2 SCLC. Some retrospective studies found that surgery improved survival in this group. A single-center study of SCLC patients, including 


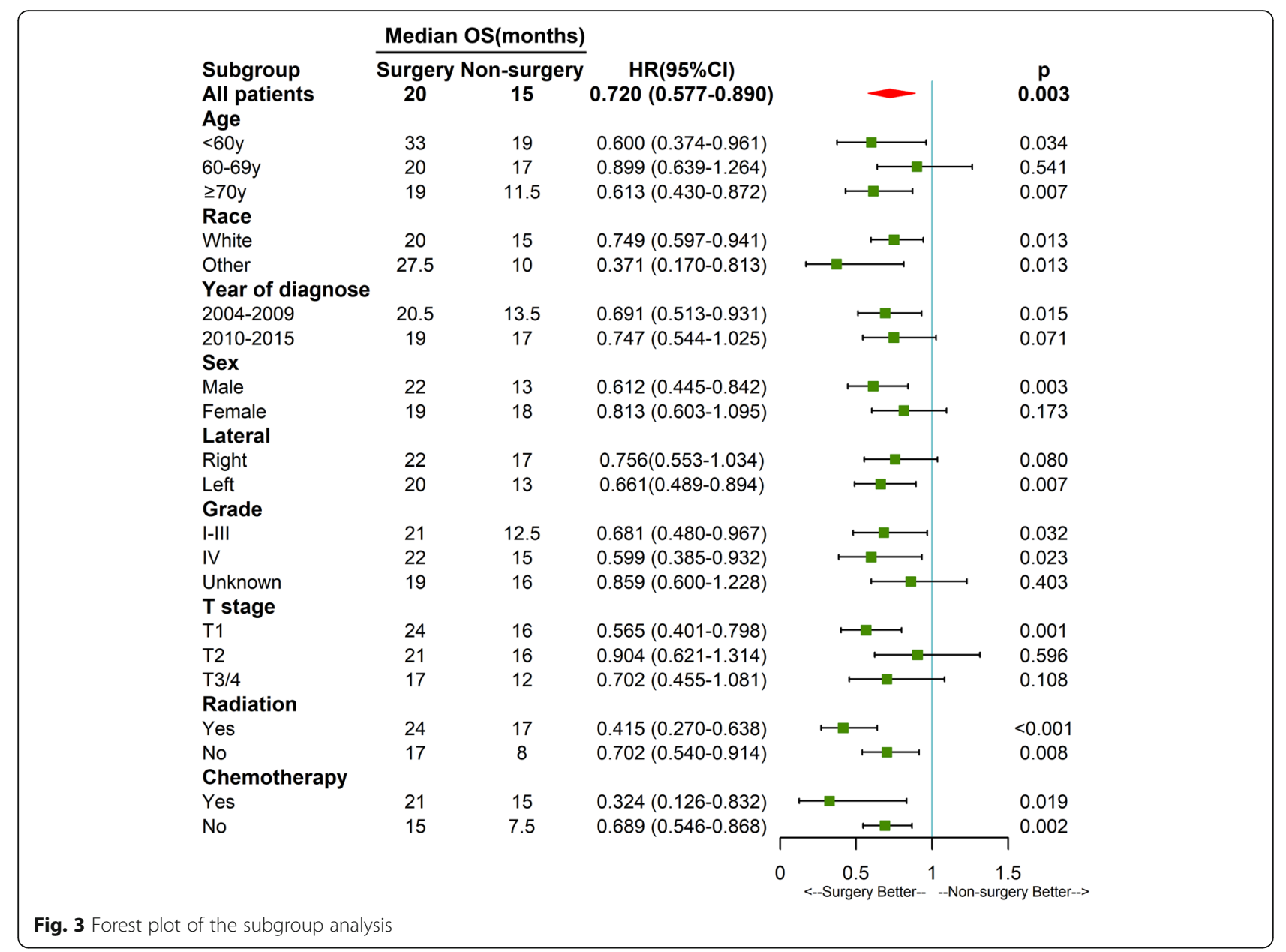

Table 3 Detailed information in patients with surgery

\begin{tabular}{ll}
\hline Variable & $\boldsymbol{N}(\%)$ \\
\hline $\begin{array}{l}\text { Procedure } \\
\text { Sublobectomy }\end{array}$ & $78(37.0)$ \\
Lobectomy & $126(59.7)$ \\
Pneumonectomy & $7(3.3)$ \\
Number of examined lymph nodes & \\
$\leq 6$ & $63(29.9)$ \\
$\geq 7$ & $101(47.9)$ \\
Unknown & $47(22.3)$ \\
Number of positive lymph nodes & \\
$\leq 2$ & $100(47.4)$ \\
$\geq 3$ & $67(31.8)$ \\
Unknown & $44(20.9)$ \\
Therapy & \\
Surgery alone & $29(13.7)$ \\
Surgery + chemotherapy & $50(23.7)$ \\
Surgery + radiation & $7(3.3)$ \\
Surgery + chemoradiation & $125(59.2)$ \\
\hline
\end{tabular}

59 stage III patients with N2 disease, reported a 5-year survival rate of 39\% [5]. In another investigation, the 5 -year survival rate after surgery in patients with stage IIIA SCLC was $30.2 \%$, which was higher than that in patients who had not undergone surgery [13]. Analyses of stage IIIA SCLC cases in the SEER database also demonstrated that surgery enhanced survival over chemoradiation $[12,14]$. However, the clinical benefit of surgery remains controversial; a retrospective study comparing the outcomes of SCLC patients following surgery and chemoradiation found similar survival rates for patients with stage IIIA disease [30]. Our analyses focused on N2 disease; in these patients, surgery achieved longer OS than radiation and chemotherapy. In agreement with earlier studies [12, 14], patients with T1 disease had longer survival than those with advanced $\mathrm{T}$ stage and also experienced a greater survival benefit from surgery, indicating that surgery is more effective in stage T1N2MO SCLC. 
Table 4 Cox regression analyses of prognostic variables for OS in surgery patients

\begin{tabular}{|c|c|c|c|c|}
\hline \multirow[t]{2}{*}{ Variable } & \multicolumn{2}{|l|}{ Univariate analysis } & \multicolumn{2}{|c|}{ Multivariate analysis } \\
\hline & HR $(95 \% \mathrm{Cl})$ & $p$ & HR $(95 \% \mathrm{Cl})$ & $p$ \\
\hline Age & $1.020(1.000-1.040)$ & 0.036 & $1.018(1.000-1.037)$ & 0.046 \\
\hline Race & $0.831(0.496-1.390)$ & 0.484 & & \\
\hline Sex & $1.040(0.758-1.420)$ & 0.824 & & \\
\hline Year & $0.947(0.690-1.300)$ & 0.739 & & \\
\hline Lateral & $1.050(0.946-1.160)$ & 0.365 & & \\
\hline Procedure & & 0.907 & & \\
\hline Sublobectomy & 1 & & & \\
\hline Lobectomy & $0.953(0.689-1.318)$ & 0.772 & & \\
\hline Pneumonectomy & $1.119(0.483-2.592)$ & 0.794 & & \\
\hline Number of examined lymph nodes & & 0.348 & & \\
\hline$\leq 6$ & 1 & & & \\
\hline$\geq 7$ & $1.031(0.715-1.486)$ & 0.872 & & \\
\hline Unknown & $1.335(0.876-2.034)$ & 0.179 & & \\
\hline Number of positive lymph nodes $\geq 3$ or unknown vs $\leq 2$ & $1.510(1.100-2.070)$ & 0.010 & $1.447(1.048-1.998)$ & 0.025 \\
\hline T stage & & 0.022 & & \\
\hline T1 & 1 & & 1 & \\
\hline $\mathrm{T} 2$ & $1.406(0.979-2.021)$ & 0.065 & $1.325(0.919-1.910)$ & 0.132 \\
\hline $\mathrm{T} 3 / \mathrm{T} 4$ & $1.718(1.154-2.557)$ & 0.008 & $1.708(1.135-2.571)$ & 0.010 \\
\hline Radiation & $0.640(0.466-0.879)$ & 0.006 & $0.684(0.478-0.981)$ & 0.039 \\
\hline Chemotherapy & $0.684(0.462-1.010)$ & 0.059 & $0.784(0.505-1.217)$ & 0.278 \\
\hline
\end{tabular}

OS overall survival, $\mathrm{Cl}$ confidence interval, $H R$ hazards ratio

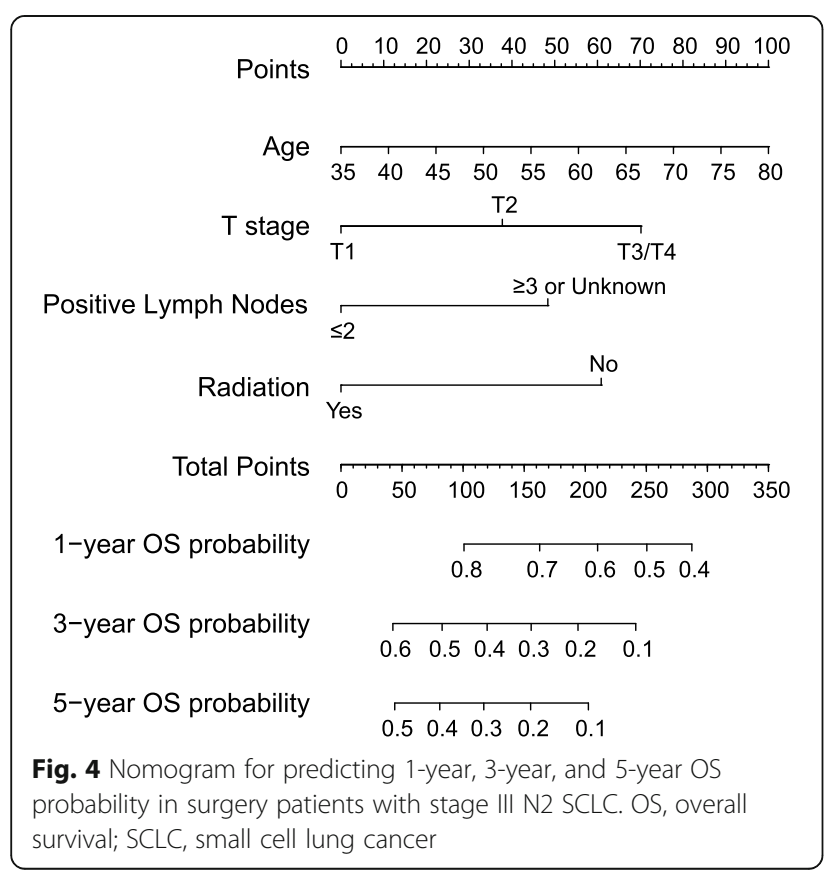

Radiation was also an independent prognostic factor for improved OS in our study, consistent with previous findings [12]. We also noticed a trend of prolonged survival in non-surgery patients treated with chemoradiation in 2010-2015 compared to those who were treated in 2004-2009 (HR $=0.887,95 \%$ CI $0.827-0.950 ; p<$ 0.001) (Figure S3). This may be attributable to the availability of new radiation regimens in recent years including stereotactic ablative radiation, accelerated hypofractionated radiation, and intensity-modulated radiation therapy, which were shown to improve survival and regional tumor control rate without increasing the adverse event rate [31-33]. Brain metastasis is common after surgery in N2 SCLC, and survival probability can be improved by postsurgical prophylactic cranial irradiation [13, 34]. Thus, radiation is an important adjuvant therapy option for SCLC management.

SCLC is highly sensitive to chemotherapy, and numerous randomized control clinical trials have demonstrated the efficacy of chemotherapy in SCLC. An etoposide and cisplatin regimen with concurrent radiation is recommended as standard treatment for LD-SCLC and was shown to enhance survival and was well tolerated [23, 35-37]. Although chemotherapy was associated with longer survival in our analysis, the impact was not 


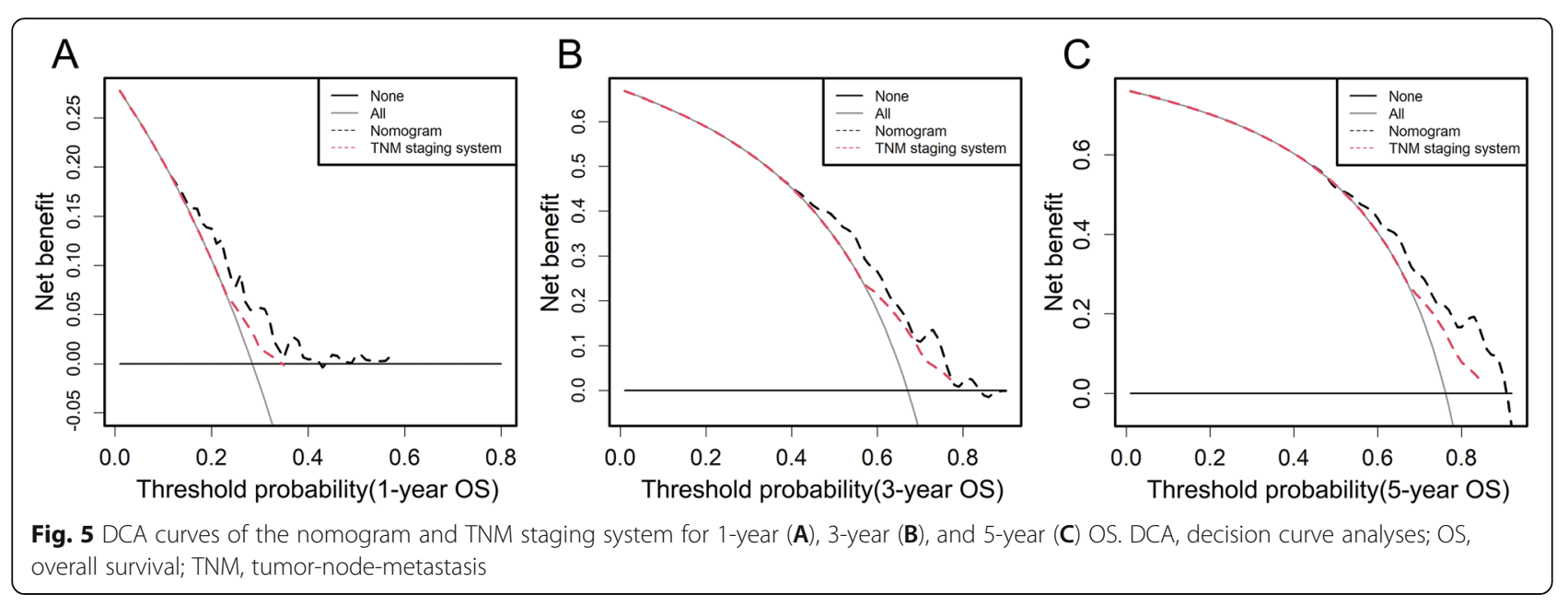

statistically significant, which is contrary to previous reports $[25,38]$. This may be due to relatively small number of patients who did not receive chemotherapy. Additionally, a correlation was observed between patients with chemotherapy and radiation $(r=0.304 ; p<$ 0.001 ). Treatment with surgery plus chemoradiation was superior to other regimens $(\mathrm{HR}=0.600,95 \% \mathrm{CI} 0.438-$ $0.822, p=0.0015$ ) (Figure S4), with a 5-year survival rate of $31.3 \%$ and median OS of 29 months (95\% CI 19-39 months). Therefore, chemoradiation is recommended as an adjuvant treatment following surgery in stage III N2 SCLC.

The selection of operable patients is critical for the effective surgical treatment of N2 SCLC. We analyzed prognostic factors in surgery patients and found that stage $\mathrm{T} 1$ and $\leq 2$ positive lymph nodes were associated with better outcome. Thus, a precise staging scheme is essential for clinical decision-making. Positron emission tomography/computed tomography is a well-established technique for SCLC staging that can detect more metastatic foci than other diagnostic methods, which has been linked to longer survival in LD-SCLC and is useful for identifying operable patients based on distant metastasis and lymph node involvement $[19,39]$. Endobronchial ultrasound-guided transbronchial needle aspiration and mediastinoscopy are minimally invasive techniques that are also important for confirming lymph node metastasis for accurate tumor staging prior to surgery $[40,41]$.

As for NSCLC, lobectomy is a standard procedure for the surgical management of SCLC, with demonstrated benefits over other procedures [42]. However, our study showed that it did not improve prognosis, with a median survival of 20 months for sublobectomy, 21 months for lobectomy, and 16 months for pneumonectomy ( $p=$ 0.90). This may be due to the smaller tumor size in sublobectomy compared to lobectomy and pneumonectomy (median, 18 vs. 27.5 vs. $42 \mathrm{~mm} ; p<0.001$ ). Lymph node status is closely related to surgical outcome, and several studies have also shown that lymph node metastasis
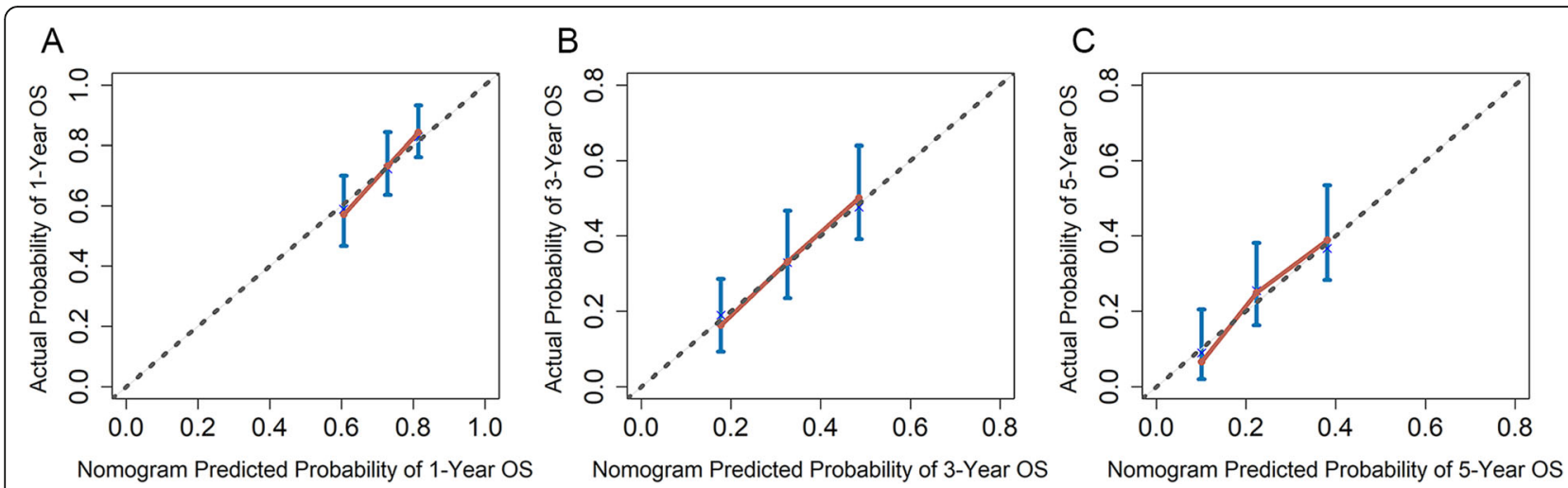

Fig. 6 The calibration plots for predicting OS probability at 1 year $(\mathbf{A}), 3$ years (B), and 5 years $(\mathbf{C})$ in the patients with surgery. OS, overall survival 


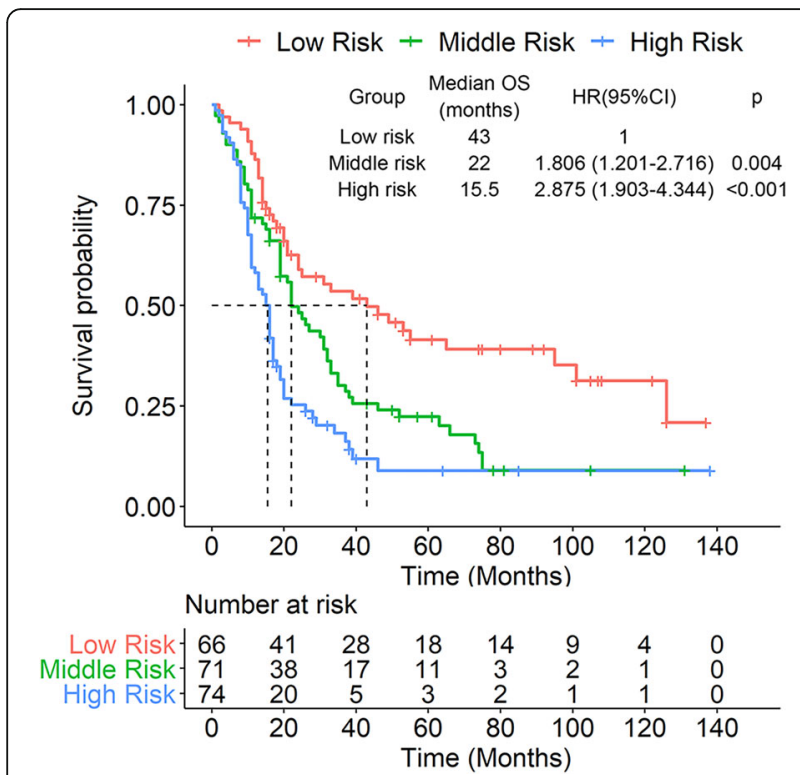

Fig. 7 The Kaplan-Meier survival curves according to prognostic score of the nomogram

predicts surgical outcome in SCLC [5, 38]. Thus, mediastinal lymph node dissection should be performed in surgical treatment.

In this study, we developed a nomogram for predicting outcome of stage III N2 SCLC following surgery. Cindex, DCA, IDI, and time-dependent ROC showed good discrimination between the nomogram and TNM staging system. When compared with the previous nomogram, this nomogram showed similar effect in predicting the survival with less predictors, which indicated more useful and convenient application in this specific stage of disease.

There were several limitations to this study. Firstly, the SEER database was missing essential information such as performance status, complications, smoking history, and cardiopulmonary function that may have influenced treatment selection. Nonetheless, as the survival of patients with stage III N2 SCLC who underwent surgery was similar to that of non-surgery patients with IA-IIB SCLC in the SEER database, the effect of surgery should not be ignored. Secondly, we were unable to obtain information on the exact chemotherapy and radiation regimens and could not evaluate the effect of standard treatments on survival. Thirdly, details of the surgery such as resection margin and lymph nodes detection were unavailable and their impact could not be assessed in the nomogram. Tumor biomarkers, such as cyclindependent kinase 5 [43], neuron-specific enolase [44], and delta-like protein 3 [45], were reported to be prognostic factors in previous studies. However, such data were still missing in SEER database. Finally, although we used PSM to balance the differences between the surgery and non-surgery groups, treatment bias could not be eliminated.

\section{Conclusions}

In conclusion, the results of our study show that surgery improved OS in operable patients with stage III N2 SCLC, especially those in stage T1. We also identified the number of positive lymph nodes as a prognostic factor in SCLC patients treated with surgery. Based on these results, we developed a nomogram for predicting OS in these patients that showed good accuracy and reliability. Prospective studies are needed to validate our findings, and more detailed information is required for the selection of operable SCLC patients.

\section{Abbreviations}

AJCC: American Joint Committee on Cancer; SCLC: Small cell lung cancer; NSCLC: Non-small cell lung cancer; OS: Overall survival; SEER: Surveillance, Epidemiology, and End Results; VALCSG: The Veterans Administration Lung Cancer Study Group; NCCN: National Comprehensive Cancer Network; LD: Limited disease; HR: Hazard ratio; Cl: Confidence interval; PSM: Propensity score matching; TNM: Tumor-node-metastasis; DCA: Decision curve analyses; IDI: Integrated discrimination improvement; AUC: Area under the curve; ROC: Receiver operating characteristics

\section{Supplementary Information}

The online version contains supplementary material available at https://doi. org/10.1186/s12957-021-02364-6.

Additional file 1. Figure S1: AUC of time-dependent ROC for the nomogram and the TNM staging system. AUC was calculated for each month from 10 to 100 months(A). The curve of the difference of the two timedependent AUCs over time was also plotted(B). AUC, area under the curve; ROC, receiver operating characteristics; TNM, tumor-nodemetastasis.

Additional file 2. Figure S2: AUC of time-dependent ROC for the developed nomogram and a previous nomogram. AUC was calculated for each month from 10 to 100 months(A). The curve of the difference of the two time-dependent AUCs over time was also plotted(B). AUC, area under the curve; ROC, receiver operating characteristics.

Additional file 3. Figure S3: Kaplan-Meier survival curves for non-surgery patients treated with chemoradiation in 2010-2015 compared with those treated in 2004-2009.

Additional file 4. Figure S4: Kaplan-Meier survival curves for surgery patients treated with chemoradiation and other regimens.

Additional file 5. Table S1 Point assignment and prognostic score in nomogram. Table S2 The AUCs of the nomogram and TNM staging system from 1 to 5 years.

\section{Acknowledgements}

The authors gratefully acknowledge the efforts of the SEER Program for providing high-quality open resources for researchers.

\section{Authors' contributions}

YC, HL, and $L$ designed the study. YC, YM, and WF collected and analyzed the data and drafted the manuscript. YM and WF revised the manuscript and contributed to data interpretation. The authors read and approved the final manuscript.

\section{Funding}

This work was supported by National Natural Science Foundation of China [grant number 81870352], Hunan Province Science and Health Union Foundation [grant number 2018JJ6135], and the Key Research and Development Project of Hunan Province [grant number 2020SK2087]. 


\section{Availability of data and materials}

The datasets analyzed during the current study are available in the Surveillance Epidemiology End Results database at https://www.seer.cancer. gov.

\section{Declarations}

\section{Ethics approval and consent to participate}

The study was conducted in accordance with the Declaration of Helsinki (as revised in 2013). The study was approved by Medical Ethics Committee of the Third Xiangya Hospital of Central South University (no. 20052; date, Dec $28,2020)$ and individual consent for this retrospective analysis was waived.

\section{Consent for publication}

Not applicable.

\section{Competing interests}

The authors declare that they have no competing interests.

Received: 12 May 2021 Accepted: 10 August 2021

Published online: 30 August 2021

\section{References}

1. Siegel RL, Miller KD, Jemal A. Cancer statistics, 2020. CA Cancer J Clin. 2020; 70(1):7-30. https://doi.org/10.3322/caac.21590.

2. Ferlay J, Ervik M, Lam F, et al. Global Cancer Observatory: cancer today: International Agency for Research on Cancer; 2020. https://gco.iarc.fr/today. Last accessed: January 13, 2021

3. Kalemkerian GP, Akerley W, Bogner P, Borghaei H, Chow LQ, Downey RJ, et al. Small cell lung cancer. J Natl Compr Cancer Netw. 2013;11(1):78-98. https://doi.org/10.6004/jnccn.2013.0011.

4. Howlader N, Noone A, Krapcho M, Miller D, Brest A, Yu M, et al. SEER Cancer Statistics Review, 1975-2017. Bethesda: National Cancer Institute; 2020. https://seer.cancer.gov/csr/1975_2017/. [based on November 2019 SEER data submission, posted to the SEER web site, April 2020]

5. Zhao X, Kallakury B, Chahine JJ, Hartmann D, Zhang Y, Chen Y, et al. Surgical resection of SCLC: prognostic factors and the tumor microenvironment. J Thorac Oncol. 2019;14(5):914-23. https://doi.org/10.101 6/j.jtho.2019.01.019.

6. Uprety D, Arjyal L, Vallatharasu Y, Bista A, Borgert A, Fitzsimmons AJ, et al. Utilization of surgery and its impact on survival in patients with early stage small-cell lung cancer in the United States. Clin Lung Cancer. 2020;21(2): 186-93 e2. https://doi.org/10.1016/j.cllc.2019.07.013.

7. Raman V, Jawitz OK, Yang CJ, Voigt SL, D'Amico TA, Harpole DH, et al. The effect of extent of resection on outcomes in patients with limited stage small cell lung cancer. J Thorac Cardiovasc Surg. 2021;161(4):1484-92 e5. https://doi.org/10.1016/j.jtcvs.2020.02.135.

8. Yang CJ, Chan DY, Shah SA, Yerokun BA, Wang XF, D'Amico TA, et al. Longterm survival after surgery compared with concurrent chemoradiation for node-negative small cell lung cancer. Ann Surg. 2018;268(6):1105-12. https://doi.org/10.1097/SLA.0000000000002287.

9. Zhong L, Suo J, Wang Y, Han J, Zhou H, Wei H, et al. Prognosis of limitedstage small cell lung cancer with comprehensive treatment including radical resection. World J Surg Oncol. 2020;18(1):27. https://doi.org/10.1186/ s12957-020-1807-1.

10. Koizumi T, Fukushima T, Hamanaka K, Shiina T, Yoshida K, Kondo R, et al, Surgical outcomes in patients with small cell lung cancer: comparative analysis of computed tomograpy-detected patients with others. World $J$ Surg Oncol. 2013;11(1):61. https://doi.org/10.1186/1477-7819-11-61.

11. Combs SE, Hancock JG, Boffa DJ, Decker RH, Detterbeck FC, Kim AW. Bolstering the case for lobectomy in stages I, II, and IIIA small-cell lung cancer using the National Cancer Data Base. J Thorac Oncol. 2015;10(2):31623. https://doi.org/10.1097/JTO.0000000000000402.

12. Zhang C, Li C, Shang $X$, Lin J, Wang H. Surgery as a potential treatment option for patients with stage III small-cell lung cancer: a propensity score matching analysis. Front Oncol. 2019;9:1339. https://doi.org/10.3389/fonc.2 019.01339 .

13. Yin K, Song D, Zhang H, Cai F, Chen J, Dang J. Efficacy of surgery and prophylactic cranial irradiation in stage II and III small cell lung cancer. J Cancer. 2018;9(19):3500-6. https://doi.org/10.7150/jca.26157.
14. Yang Y, Yuan G, Zhan C, Huang Y, Zhao M, Yang X, et al. Benefits of surgery in the multimodality treatment of stage IIB-IIIC small cell lung cancer. J Cancer. 2019;10(22):5404-12. https://doi.org/10.7150/jca.31202.

15. Park BJ, Kim TH, Shin S, Kim HK, Choi YS, Kim J, et al. Recommended change in the $\mathrm{N}$ descriptor proposed by the International Association for the Study of Lung Cancer: a validation study. J Thorac Oncol. 2019;14(11): 1962-9. https://doi.org/10.1016/j.jtho.2019.07.034.

16. Martins RG, D'Amico TA, Loo BW Jr, Pinder-Schenck M, Borghaei H, Chaft JE, et al. The management of patients with stage IIIA non-small cell lung cancer with N2 mediastinal node involvement. J Natl Compr Cancer Netw. 2012;10(5):599-613. https://doi.org/10.6004/jnccn.2012.0062.

17. Albain KS, Swann RS, Rusch WW, Turrisi AT 3rd, Shepherd FA, Smith C, et al. Radiotherapy plus chemotherapy with or without surgical resection for stage III non-small-cell lung cancer: a phase III randomised controlled trial. Lancet. 2009;374(9687):379-86. https://doi.org/10.1016/S0140-6736(09)6073 7-6.

18. Zeng Q, Li J, Tan F, Sun N, Mao Y, Gao Y, et al. Development and validation of a nomogram prognostic model for resected limited-stage small cell lung cancer patients. Ann Surg Oncol. 2021;28(9):4893-904. https://doi.org/10.124 5/s10434-020-09552-w.

19. Hong JC, Boyer MJ, Spiegel DY, Williams CD, Tong BC, Shofer SL, et al. Increasing PET use in small cell lung cancer: survival improvement and stage migration in the VA Central Cancer Registry. J Natl Compr Cancer Netw. 2019;17(2):127-39. https://doi.org/10.6004/jnccn.2018.7090.

20. Fox W, Scadding JG. Medical Research Council comparative trial of surgery and radiotherapy for primary treatment of small-celled or oat-celled carcinoma of bronchus. Ten-year follow-up. Lancet. 1973;2(7820):63-5. https://doi.org/10.1016/s0140-6736(73)93260-1.

21. Osterlind K, Hansen M, Hansen HH, Dombernowsky P, Rorth M. Treatment policy of surgery in small cell carcinoma of the lung: retrospective analysis of a series of 874 consecutive patients. Thorax. 1985;40(4):272-7. https://doi. org/10.1136/thx.40.4.272.

22. Lad T, Piantadosi S, Thomas P, Payne D, Ruckdeschel J, Giaccone G. A prospective randomized trial to determine the benefit of surgical resection of residual disease following response of small cell lung cancer to combination chemotherapy. Chest. 1994;106(6 Suppl):320S-3S. https://doi. org/10.1378/chest.106.6_supplement.320s.

23. Sundstrom S, Bremnes RM, Kaasa S, Aasebo U, Hatlevoll R, Dahle R, et al. Cisplatin and etoposide regimen is superior to cyclophosphamide, epirubicin, and vincristine regimen in small-cell lung cancer: results from a randomized phase III trial with 5 years' follow-up. J Clin Oncol. 2002;20(24): 4665-72. https://doi.org/10.1200/JCO.2002.12.111.

24. Kubota K, Hida T, Ishikura S, Mizusawa J, Nishio M, Kawahara M, et al. Etoposide and cisplatin versus irinotecan and cisplatin in patients with limited-stage small-cell lung cancer treated with etoposide and cisplatin plus concurrent accelerated hyperfractionated thoracic radiotherapy (JCOG0202): a randomised phase 3 study. Lancet Oncol. 2014;15(1):106-13. https://doi.org/10.1016/S1470-2045(13)70511-4.

25. Wang $Y$, Zheng $Q$, Jia $B, A n T$, Zhao J, Wu M, et al. Effects of surgery on survival of early-stage patients with SCLC: propensity score analysis and nomogram construction in SEER Database. Front Oncol. 2020;10:626. https:// doi.org/10.3389/fonc.2020.00626.

26. Liu J, Zhou H, Zhang Y, Fang W, Yang Y, Hong S, et al. Cause-specific death assessment of patients with stage I small-cell lung cancer: a competing risk analysis. Future Oncol. 2019;15(21):2479-88. https://doi.org/10.2217/fon-201 8-0888.

27. Yu JB, Decker RH, Detterbeck FC, Wilson LD. Surveillance epidemiology and end results evaluation of the role of surgery for stage I small cell lung cancer. J Thorac Oncol. 2010;5(2):215-9. https://doi.org/10.1097/JTO.0b013e3181cd3208.

28. Casiraghi M, Sedda G, Del Signore E, Piperno G, Maisonneuve P, Petrella F, et al. Surgery for small cell lung cancer: When and how. Lung Cancer. 2021; 152:71-7. https://doi.org/10.1016/j.lungcan.2020.12.006.

29. Faivre-Finn C, Snee M, Ashcroft L, Appel W, Barlesi F, Bhatnagar A, et al. Concurrent once-daily versus twice-daily chemoradiotherapy in patients with limited-stage small-cell lung cancer (CONVERT): an open-label, phase 3, randomised, superiority trial. Lancet Oncol. 2017;18(8):1116-25. https://doi. org/10.1016/S1470-2045(17)30318-2.

30. Chen MY, Hu X, Bao Y, Wang J, Chen YM, Xu YJ, et al. Comparison of long term results between matched chemoradiotherapy and surgery for limited stage small cell lung cancer. Cancer Manag Res. 2019;11:9049-55. https:// doi.org/10.2147/CMAR.S222882. 
31. Zayed S, Chen H, Ali E, Rodrigues GB, Warner A, Palma DA, et al. Is there a role for hypofractionated thoracic radiation therapy in limited-stage small cell lung cancer? A propensity score matched analysis. Int J Radiat Oncol Biol Phys. 2020;108(3):575-86. https://doi.org/10.1016/j.ijrobp.2020.06.008.

32. Stahl JM, Corso CD, Verma V, Park HS, Nath SK, Husain ZA, et al. Trends in stereotactic body radiation therapy for stage I small cell lung cancer. Lung Cancer. 2017;103:11-6. https://doi.org/10.1016/j.lungcan.2016.11.009.

33. Liu Z, Wang J, Yuan Z, Zhang B, Gong L, Zhao L, et al. Preliminary results about application of intensity-modulated radiotherapy to reduce prophylactic radiation dose in limited-stage small cell lung cancer. J Cancer. 2018;9(15):2625-30. https://doi.org/10.7150/jca.24976.

34. Resio BJ, Hoag J, Chiu A, Monsalve A, Dhanasopon AP, Boffa DJ, et al. Prophylactic cranial irradiation is associated with improved survival following resection for limited stage small cell lung cancer. J Thorac Dis. 2019:11(3):811-8. https://doi.org/10.21037/jtd.2019.01.64.

35. Skarlos DV, Samantas E, Briassoulis E, Panoussaki E, Pavlidis N, Kalofonos HP, et al. Randomized comparison of early versus late hyperfractionated thoracic irradiation concurrently with chemotherapy in limited disease small-cell lung cancer: a randomized phase II study of the Hellenic Cooperative Oncology Group (HeCOG). Ann Oncol. 2001;12(9):1231-8. https://doi.org/10.1023/a:1012295131640.

36. Yang CF, Chan DY, Speicher PJ, Gulack BC, Wang X, Hartwig MG, et al. Role of adjuvant therapy in a population-based cohort of patients with earlystage small-cell lung cancer. J Clin Oncol. 2016;34(10):1057-64. https://doi. org/10.1200/JCO.2015.63.8171.

37. Brock MV, Hooker CM, Syphard JE, Westra W, Xu L, Alberg AJ, et al. Surgical resection of limited disease small cell lung cancer in the new era of platinum chemotherapy: its time has come. J Thorac Cardiovasc Surg. 2005; 129(1):64-72. https://doi.org/10.1016/j.jtcvs.2004.08.022.

38. Wang Y, Pang Z, Chen X, Yan T, Liu J, Du J. Development and validation of a prognostic model of resectable small-cell lung cancer: a large populationbased cohort study and external validation. J Transl Med. 2020;18(1):237. https://doi.org/10.1186/s12967-020-02412-x.

39. Martucci F, Pascale M, Valli MC, Pesce GA, Froesch P, Giovanella L, et al. Impact of (18)F-FDG PET/CT in staging patients with small cell lung cancer: a systematic review and meta-analysis. Front Med. 2019;6:336. https://doi. org/10.3389/fmed.2019.00336.

40. Bousema JE, Heineman DJ, Dijkgraaf MGW, Annema JT, van den Broek FJC. Adherence to the mediastinal staging guideline and unforeseen N2 disease in patients with resectable non-small cell lung cancer: Nationwide results from the Dutch Lung Cancer Audit - surgery. Lung Cancer. 2020;142:51-8. https://doi.org/10.1016/j.lungcan.2020.02.008

41. Annema JT, van Meerbeeck JP, Rintoul RC, Dooms C, Deschepper E, Dekkers $\mathrm{OM}$, et al. Mediastinoscopy vs endosonography for mediastinal nodal staging of lung cancer: a randomized trial. JAMA. 2010;304(20):2245-52. https://doi.org/10.1001/jama.2010.1705.

42. Turner SR, Butts CA, Debenham BJ, Stewart KC. Is lobectomy superior to sublobar resection for early-stage small-cell lung cancer discovered intraoperatively? Interact Cardiovasc Thorac Surg. 2019;28(1):41-4. https:// doi.org/10.1093/icvts/ivy223.

43. Wei K, Ye Z, Li Z, Dang Y, Chen X, Huang N, et al. An immunohistochemical study of cyclin-dependent kinase 5 (CDK5) expression in non-small cell lung cancer (NSCLC) and small cell lung cancer (SCLC): a possible prognostic biomarker. World J Surg Oncol. 2016;14(1):34. https://doi.org/10.1186/s12 957-016-0787-7.

44. Tian Z, Liang C, Zhang Z, Wen $H$, Feng $H, M a ~ Q$, et al. Prognostic value of neuron-specific enolase for small cell lung cancer: a systematic review and meta-analysis. World J Surg Oncol. 2020;18(1):116. https://doi.org/10.1186/ s12957-020-01894-9.

45. Chen B, Li H, Liu C, Wang S, Zhang F, Zhang L, et al. Potential prognostic value of delta-like protein 3 in small cell lung cancer: a meta-analysis. World J Surg Oncol. 2020;18(1):226. https://doi.org/10.1186/s12957-020-02004-5.

\section{Publisher's Note}

Springer Nature remains neutral with regard to jurisdictional claims in published maps and institutional affiliations.

Ready to submit your research? Choose BMC and benefit from:

- fast, convenient online submission

- thorough peer review by experienced researchers in your field

- rapid publication on acceptance

- support for research data, including large and complex data types

- gold Open Access which fosters wider collaboration and increased citations

- maximum visibility for your research: over $100 \mathrm{M}$ website views per year

At BMC, research is always in progress.

Learn more biomedcentral.com/submissions 